\title{
Safety of second-generation drug-eluting stents three years after randomised use in the TWENTE trial
}

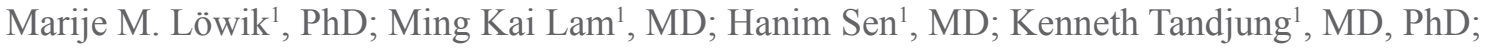 \\ K. Gert van Houwelingen ${ }^{1}$, MD; Frits H.A.F. de Man $^{1}$, MD, PhD; Martin G. Stoel ${ }^{1}$, MD, PhD; \\ J. (Hans) W. Louwerenburg ${ }^{1}$, MD; Gerard C.M. Linssen², MD, PhD; Carine J.M. Doggen ${ }^{3}$, PhD; \\ Clemens von Birgelen ${ }^{1,3 *}, \mathrm{MD}, \mathrm{PhD}$
}

1. Department of Cardiology, Thoraxcentrum Twente, Medisch Spectrum Twente, Enschede, The Netherlands; 2. Department of Cardiology, Ziekenhuisgroep Twente, Almelo and Hengelo, The Netherlands; 3. Health Technology and Services Research, MIRA - Institute for Biomedical Technology and Technical Medicine, University of Twente, Enschede, The Netherlands

M.M. Löwik and M.K. Lam contributed equally to this manuscript.

\begin{tabular}{l}
\hline KEYWORDS \\
\hline - Co-Cr EES \\
- Co-Cr R-ZES \\
- coronary \\
revascularisation \\
- everolimus-eluting \\
stent(s) \\
- long-term outcome \\
- long-term result(s) \\
- percutaneous \\
coronary \\
intervention(s) \\
- randomised study \\
- second-generation \\
drug-eluting \\
stent(s) \\
- stent(s) \\
- stent thrombosis \\
- TWENTE trial \\
- zotarolimus-eluting \\
stent(s) \\
\hline
\end{tabular}

\begin{abstract}
Aims: To assess three-year clinical outcome following randomised use of the second-generation Resolute zotarolimus-eluting stent (ZES) and the XIENCE V everolimus-eluting stent (EES). For Resolute ZES and randomised use, outcome data $\geq 3$ years are relatively scarce.

Methods and results: The TWENTE trial examined 1,391 patients with stable angina or non-ST-elevation acute coronary syndromes, of whom $21.6 \%$ were diabetics, $70.1 \%$ had complex B2 or C lesions and $77.4 \%$ had "off-label" indications for DES use. Three-year follow-up data were obtained in 1,381 patients (99.3\%; 10 withdrawals). Adverse clinical events were independently adjudicated. The primary endpoint target vessel failure (TVF), a composite of cardiac death, target vessel-related myocardial infarction and clinically indicated target vessel revascularisation, was $12.1 \%$ for Resolute ZES and $13.4 \%$ for XIENCE V EES ( $\mathrm{p}=0.50)$. Cardiac death rates were $1.9 \%$ vs. $3.5 \%(p=0.06)$; the other individual components of TVF also showed no significant between-group differences. The rates of definite-or-probable stent thrombosis $(1.4 \%$ vs. $1.6 \%$, $\mathrm{p}=0.82)$ and very late stent thrombosis $(0.6 \%$ vs. $0.4 \%, \mathrm{p}=1.0)$ did not differ between the groups.
\end{abstract}

Conclusions: Three-year follow-up data of patients included in the randomised TWENTE trial demonstrated similar and sustained safety and efficacy of Resolute ZES and XIENCE V EES.

\footnotetext{
*Corresponding author: Thoraxcentrum Twente, Department of Cardiology, Haaksbergerstraat 55, 7513 ER Enschede, The Netherlands.E-mail: c.vonbirgelen@mst.nl
} 


\section{Introduction}

Clinical follow-up data beyond two years provide valuable information on the long-term safety of drug-eluting stents (DES). The Resolute zotarolimus-eluting stent (ZES) (Medtronic Inc., Santa Rosa, CA, USA) is a second-generation DES that is widely used, but only a single randomised study, the RESOLUTE All-Comers trial, has published outcome data beyond two years ${ }^{1}$. The randomised TWENTE trial has previously demonstrated, in a broad study population, the non-inferiority of the Resolute ZES compared to the XIENCE V everolimus-eluting stent (EES) (Abbott Vascular, Santa Clara, CA, USA) ${ }^{2,3}$. Meanwhile, three-year outcome data of the TWENTE trial have been obtained, which contribute significantly to the knowledge about the longer-term safety and efficacy of second-generation DES.

\section{Methods}

Study design, definitions of clinical endpoints, characteristics of patients, lesions, procedures and the one- and two-year clinical outcomes of the investigator-initiated, patient-blinded, randomised TWENTE trial (ClinicalTrials.gov NCT01066650) have been previously reported ${ }^{2,3}$. The TWENTE trial enrolled 1,391 patients with stable angina or non-ST-elevation acute coronary syndromes, of whom $21.6 \%$ were diabetics, $70.1 \%$ had complex lesions and $77.4 \%$ fulfilled at least one criterion of off-label DES use ${ }^{2}$. More than $80 \%$ of all eligible patients were enrolled in this randomised clinical trial $^{4}$. Between two- and three-year follow-up, the external CRO Diagram (Zwolle, The Netherlands) monitored clinical outcome in $10 \%$ of randomly selected patients and organised the adjudication of adverse events by an independent clinical events committee. The TWENTE trial and follow-up have been approved by the institutional medical ethics committee, complied with the Declaration of Helsinki and patients provided written informed consent. Clinical endpoints were defined according to the Academic Research Consortium $(\mathrm{ARC})^{5}$; myocardial infarction (MI) was classified according to the extended historical definition ${ }^{6}$. Primary endpoint of TWENTE was target vessel failure (TVF) at one year, a composite of cardiac death, target vessel-related MI and clinically indicated target vessel revascularisation (TVR). A p-value $<0.05$ was considered statistically significant and statistics were performed as appropriate and corresponding to previous reports ${ }^{2,3}$ using SPSS 15.0 (SPSS Inc., Chicago, IL, USA).

\section{Results}

We obtained three-year follow-up in 1,381 patients (99.3\%; i.e., all enrolled patients except 10 withdrawals). Both the Resolute ZES and the XIENCE V EES groups showed a favourable outcome with a similar incidence of TVF (84/692 [12.1\%] vs. 92/689 [13.4\%], $\mathrm{p}_{\text {log-rank }}=0.58$; Figure 1, Table 1), a composite of cardiac death, target vessel-related MI and clinically indicated TVR. Between DES groups, there was also no significant difference in a patient-oriented composite endpoint, consisting of all-cause death, any MI or any revascularisation $(120 / 692$ [17.2\%] vs. 114/689 [16.5\%], $\mathrm{p}=0.69$; Table 1).

In addition, as shown in Table 1 and Figure 2, the rates of very late definite-or-probable stent thrombosis ( $>12$ months) were similar and low (4/692 [0.6\%] vs. $3 / 689$ [0.4\%], p=1.0). During threeyear follow-up, the rates of definite stent thrombosis (7/692 [1.0\%] vs. $2 / 689[0.3 \%], \mathrm{p}=0.18)$ and definite-or-probable stent thrombosis $(10 / 692$ [1.4\%] vs. $11 / 689$ [1.6\%), $\mathrm{p}=0.82)$ remained low and similar for both groups. At three-year follow-up, 5.0\% (33/657) of patients in the Resolute ZES group and 5.9\% (38/645) of patients in the XIENCE V EES group were on dual antiplatelet therapy (acetylsalicylic acid plus P2Y12 inhibitor).

There were also no statistically significant differences in the rates of other individual clinical endpoints such as target vessel-related MI (40/692 [5.8\%] vs. 40/689 [5.8\%], $\left.\mathrm{p}_{\text {log-rank }}=0.98\right)$, clinically indicated TVR (45/692 [6.5\%] vs. 44/689 [6.4\%], $\left.\mathrm{p}_{\text {log-rank }}=0.84\right)$ and cardiac death (13/692 [1.9\%] vs. 24/689 [3.5\%], $\mathrm{p}_{\text {log-rank }}=0.07$; Figure 1). The Kaplan-Meier curves of cardiac death

Table 1. Three-year clinical outcome and outcome difference between one and three years.

\begin{tabular}{|c|c|c|c|c|c|c|c|c|c|}
\hline & \multicolumn{4}{|c|}{ Outcome at 3 years } & \multicolumn{4}{|c|}{ Outcome difference between 1 and 3 years } \\
\hline & & $\begin{array}{l}\text { Resolute ZES } \\
(n=692)\end{array}$ & $\begin{array}{c}\text { XIENCE V } \\
\text { EES }(n=689)\end{array}$ & $\begin{array}{l}\text { Difference } \\
\text { (95\% CI) }\end{array}$ & $p$-value & $\begin{array}{c}\text { Resolute } \\
\text { ZES }\end{array}$ & $\begin{array}{l}\text { XIENCE V } \\
\text { EES }\end{array}$ & $\begin{array}{l}\text { Difference } \\
\text { (95\% CI) }\end{array}$ & $p$-value \\
\hline \multicolumn{2}{|c|}{ Target vessel failure } & $84(12.1)$ & 92 (13.4) & $-1.2(-4.7-2.3)$ & 0.50 & $4.3(27 / 628)$ & $5.7(36 / 629)$ & $-1.4(-3.8-1.0)$ & 0.25 \\
\hline Death & $\begin{array}{l}\text { Any cause } \\
\text { Cardiac cause }\end{array}$ & $\begin{array}{l}35(5.1) \\
13(1.9)\end{array}$ & $\begin{array}{l}44(6.4) \\
24(3.5)\end{array}$ & $\begin{array}{l}-1.3(-3.8-1.1) \\
-1.6(-3.3-0.1)\end{array}$ & $\begin{array}{l}0.29 \\
0.06\end{array}$ & $\begin{array}{l}3.0(20 / 677) \\
0.9(6 / 677)\end{array}$ & $\begin{array}{l}4.4(30 / 675) \\
2.1(14 / 675)\end{array}$ & $\begin{array}{l}-1.5(-3.5-0.5) \\
-1.2(-2.5-0.1)\end{array}$ & $\begin{array}{l}0.15 \\
0.07\end{array}$ \\
\hline \multicolumn{2}{|c|}{ Target vessel-related myocardial infarction } & $40(5.8)$ & $40(5.8)$ & $0.0(-2.5-2.4)$ & 0.98 & $1.2(8 / 646)$ & $1.2(8 / 647)$ & $0.0(-1.2-1.2)$ & 1.00 \\
\hline \multicolumn{2}{|c|}{ Clinically indicated target vessel revascularisation } & $45(6.5)$ & $44(6.4)$ & $0.1(-2.5-2.7)$ & 0.93 & $3.4(22 / 654)$ & $3.8(25 / 656)$ & $-0.4(-2.5-1.6)$ & 0.66 \\
\hline \multicolumn{2}{|c|}{ Target lesion failure } & $80(11.6)$ & $80(11.6)$ & $-0.1(-3.4-3.3)$ & 0.98 & $4.0(25 / 630)$ & $5.2(33 / 638)$ & $-1.2(-3.5-1.1)$ & 0.31 \\
\hline \multicolumn{2}{|c|}{ Clinically indicated target lesion revascularisation } & $37(5.3)$ & $27(3.9)$ & $1.4(-0.8-3.6)$ & 0.21 & $2.7(18 / 658)$ & $2.6(17 / 665)$ & $0.2(-1.6-1.9)$ & 0.84 \\
\hline \multicolumn{2}{|c|}{ Major adverse cardiac events } & $100(14.5)$ & $99(14.4)$ & $0.1(-3.6-3.8)$ & 0.97 & $6.1(38 / 622)$ & $7.7(48 / 627)$ & $-1.5(-4.4-1.3)$ & 0.28 \\
\hline \multicolumn{2}{|c|}{ Patient-oriented composite endpoint } & 120 (17.3) & $114(16.5)$ & $0.8(-3.2-4.8)$ & 0.69 & $9.0(55 / 614)$ & $8.6(53 / 616)$ & $0.4(-2.8-3.5)$ & 0.83 \\
\hline $\begin{array}{l}\text { Stent } \\
\text { thrombosis }\end{array}$ & $\begin{array}{l}\text { Definite } \\
\text { Definite-or-probable } \\
\text { Very late definite-or-probable* }\end{array}$ & $\begin{array}{r}7(1.0) \\
10(1.4) \\
4(0.6)\end{array}$ & $\begin{array}{r}2(0.3) \\
11(1.6) \\
3(0.4)\end{array}$ & $\begin{array}{r}0.7(-0.1-1.6) \\
-0.2(-1.4-1.1) \\
0.1(-0.6-0.9)\end{array}$ & $\begin{array}{l}0.18 \\
0.82 \\
1.00\end{array}$ & $\begin{array}{l}0.4(3 / 674) \\
0.6(4 / 672)\end{array}$ & $\begin{array}{l}0.3(2 / 675) \\
0.4(3 / 671)\end{array}$ & $\begin{array}{l}0.1(-0.5-0.8) \\
0.1(-0.6-0.8)\end{array}$ & $\begin{array}{l}0.69 \\
1.00\end{array}$ \\
\hline
\end{tabular}

Values are \% (n/N) or $n(\%)$ where appropriate. Cl: confidence interval; * definitions of clinical endpoints have previously been reported ${ }^{2}$ 

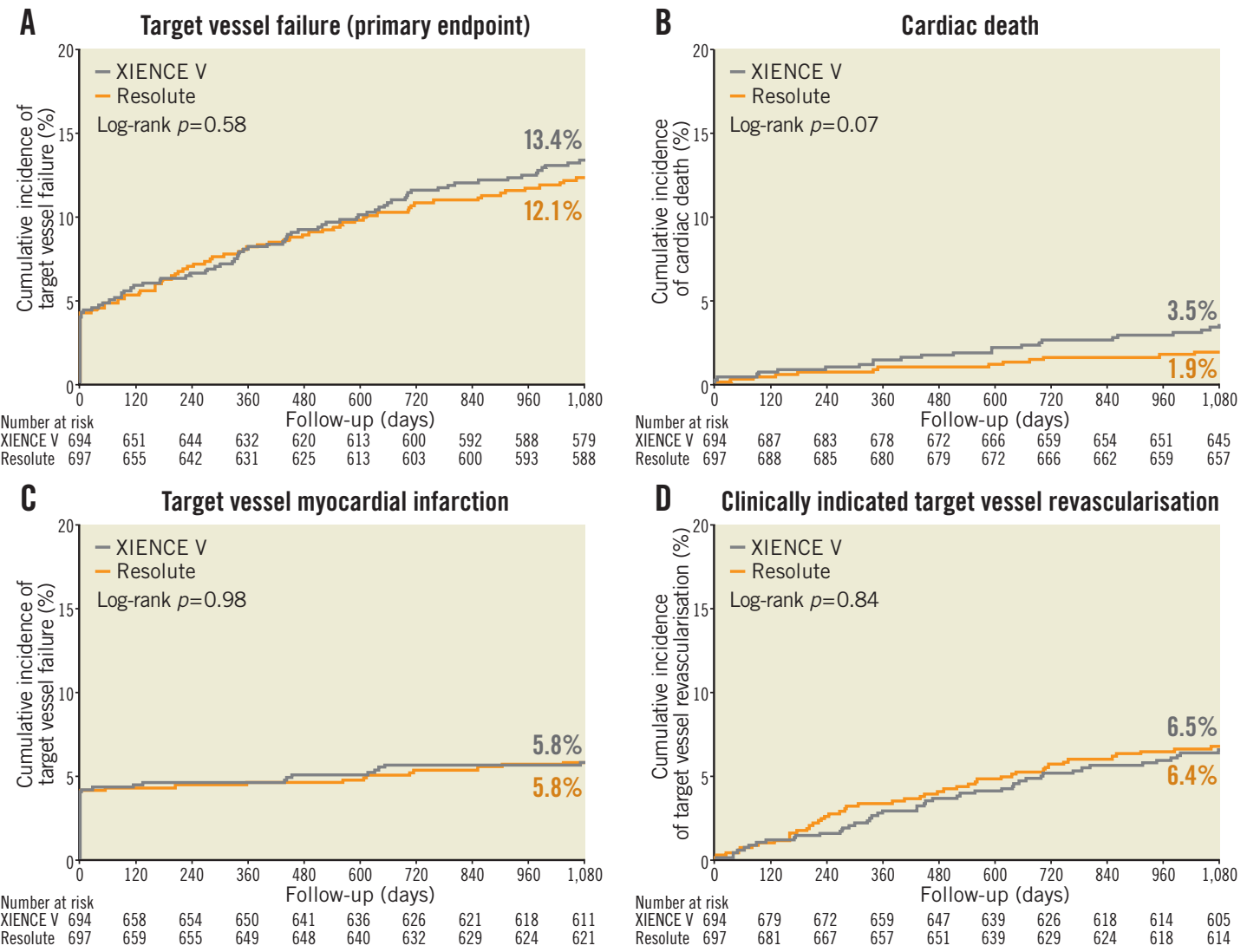

Figure 1. Kaplan-Meier curves for the composite endpoint target vessel failure (TVF) and its individual components until three-year follow-up. (A) TVF, a composite of cardiac death, target vessel-related MI and target vessel revascularisation; (B) cardiac death; (C) target vesselrelated MI; (D) target vessel revascularisation. P-values were derived from the log-rank test; they may differ from p-values reported in the manuscript, which were derived from $\chi^{2}$ analysis.

tended to diverge after one year. We therefore performed post hoc a one-year landmark analysis which showed no significant difference in cardiac death during the first year (7/695 [1.0\%] vs. $10 / 692[1.4 \%], \mathrm{p}_{\text {log-rank }}=0.46$; HR $1.43,95 \% \mathrm{CI}: 0.55-3.77$ ) and, beyond one year, there was only a statistically non-significant trend $\left(6 / 677[0.9 \%]\right.$ vs. $14 / 675[2.1 \%], \mathrm{p}_{\text {log-rank }}=0.08 ;$ HR 2.19, 95\% CI: 0.83-5.77; patients who died during the first year were excluded).

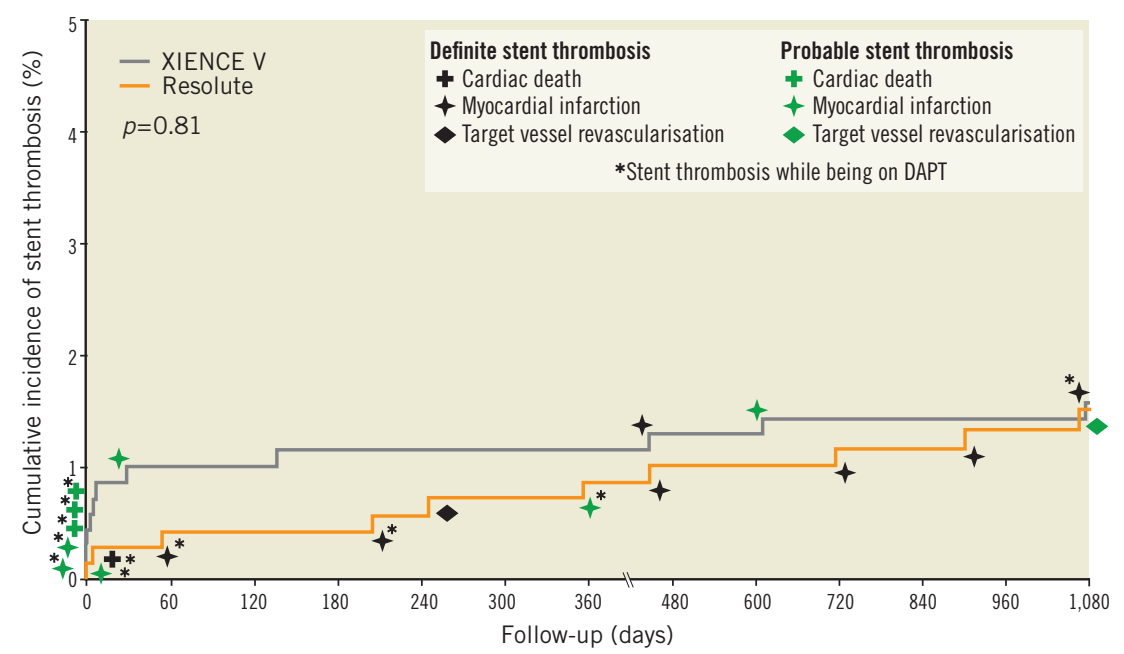

Figure 2. Cumulative incidence of definite-or-probable stent thrombosis at three-year follow-up. The cumulative incidence of definite-orprobable stent thrombosis, according to the Academic Research Consortium definition, is shown. DAPT: dual antiplatelet therapy (i.e., acetylsalicylic acid plus P2Y12 receptor antagonist) 


\section{Discussion}

Only very limited long-term data of randomised trial populations with $\geq$ three-year follow-up are available for the second-generation Resolute ZES. The present three-year clinical outcome data of the TWENTE trial that were obtained from 1,381 (99.3\% of all enrolled) patients corroborate the favourable long-term outcome in the RESOLUTE All Comers trial, which is the only other randomised DES trial that reported $\geq$ three-year clinical outcome of Resolute ZES ${ }^{1}$. The observed trend towards a lower cardiac mortality in TWENTE patients treated with Resolute ZES cannot be explained by baseline or procedural data. It might be a play of chance. Nevertheless, further assessment of clinical follow-up of this study population is of interest.

This study was not powered to assess between-group differences in secondary clinical endpoints, such as cardiac death. In addition, our findings may not be generalised to patients with an acute ST-elevation MI (first 48 hours), as such patients were not enrolled in TWENTE.

\section{Conclusion}

The present three-year follow-up of the TWENTE trial demonstrates a similar and sustained safety and efficacy of the secondgeneration Resolute ZES and XIENCE V EES.

\section{Impact on daily practice}

The favourable three-year outcome data after use of both permanent-polymer drug-eluting stents (DES) in the broad study population of the TWENTE randomised trial, which comprised a real-world patient population with many patients who had complex lesions and various comorbid conditions, are a strong signal of sustained safety and efficacy of the compared devices in clinical practice. In addition, the consistently low rates of adverse clinical events such as stent thrombosis, target vessel-related myocardial infarction and repeat revascularisation, which were similar for both DES, represent an important benchmark for future comparison with long-term outcome data to be obtained after the use of novel DES and biodegradable scaffolds in complex patients.

\section{Funding}

The investigator-initiated TWENTE trial had been supported by equal unrestricted grants from Abbott Vascular and Medtronic. The present three-year follow-up of patients randomised in TWENTE has been supported by a grant from Medtronic.

\section{Conflict of interest statement}

C. von Birgelen is or has been consultant to and has received lecture fees or travel expenses from Abbott Vascular, Boston Scientific, and Medtronic; he received travel expenses from Biotronik and lecture fees from MSD; the institution has received research grants from Abbott Vascular, Biotronik, Boston Scientific, and Medtronic. All other authors have no further conflicts of interest to declare.

\section{References}

1. Taniwaki M, Stefanini GG, Silber S, Richardt G, Vranckx P, Serruys PW, Buszman PE, Kelbaek H, Windecker S. Four year clinical outcomes and predictors of repeat revascularization in patients treated with new generation drug-eluting stents in the RESOLUTE All Comers Randomized Trial. J Am Coll Cardiol. 2014;63:1617-25.

2. von Birgelen C, Basalus MW, Tandjung K, van Houwelingen KG, Stoel MG, Louwerenburg JH, Linssen GC, Saïd SA, Kleijne MA, Sen H, Löwik MM, van der Palen J, Verhorst PM, de Man FH. A randomized controlled trial in second-generation zotarolimuseluting Resolute stents versus everolimus-eluting Xience V stents in real-world patients: the TWENTE trial. J Am Coll Cardiol. 2012;59:1350-61.

3. Tandjung K, Sen H, Lam MK, Basalus MW, Louwerenburg JH, Stoel MG, van Houwelingen KG, de Man FH, Linssen GC, Saïd SA, Nienhuis MB, Löwik MM, Verhorst PM, van der Palen J, von Birgelen C. Clinical outcome following stringent discontinuation of dual antiplatelet therapy after 12 months in real-world patients treated with second-generation zotarolimus-eluting resolute and everolimus-eluting Xience V stents: 2-year follow-up of the randomized TWENTE trial. J Am Coll Cardiol. 2013;61:2406-16.

4. Sen H, Tandjung K, Basalus MW, Löwik MM, van Houwelingen GK, Stoel MG, Louwerenburg HW, de Man FH, Linssen GC, Nijhuis R, Nienhuis MB, Verhorst PM, van der Palen J, von Birgelen C. Comparison of eligible non-enrolled patients and the randomised TWENTE trial population treated with Resolute and Xience V drug-eluting stents. EuroIntervention. 2012;8:664-71.

5. Cutlip DE, Windecker S, Mehran R, Boam A, Cohen DJ, van Es GA, Steg PG, Morel MA, Mauri L, Vranckx P, McFadden E, Lansky A, Hamon M, Krucoff MW, Serruys PW; Academic Research Consortium. Clinical end points in coronary stent trials: a case for standardized definitions. Circulation. 2007;115:2344-51.

6. Vranckx P, Cutlip DE, Mehran R, Kint PP, Silber S, Windecker S, Serruys PW. Myocardial infarction adjudication in contemporary all-comer stent trials: balancing sensitivity and specificity. Addendum to the historical MI definitions used in stent studies. EuroIntervention. 2010;5:871-4. 